\title{
DOSE-DEPENDENT RELATIONSHIP BETWEEN PRENATAL EXPOSURE TO FINE PARTICULATES AND EXHALED CARBON MONOXIDE IN NON-ASTHMATIC CHILDREN. A POPULATION-BASED BIRTH COHORT STUDY
}

WIESŁAW A. JĘDRYCHOWSKI ${ }^{1}$, UMBERTO MAUGERI ${ }^{2}$, JOHN SPENGLER ${ }^{3}$, ELŻBIETA MRÓZ ${ }^{1}$, ELŻBIETA FLAK $^{1}$, MARIA KLIMASZEWSKA-REMBIASZ ${ }^{4}$, RYSZARD JACEK ${ }^{1}$, and AGATA SOWA ${ }^{1}$

${ }^{1}$ Jagiellonian University Medical College, Kraków, Poland

Chair of Epidemiology and Preventive Medicine

${ }^{2}$ Institute for Clinical Medicine and Rehabilitation, Pavia, Italy

${ }^{3}$ Harvard School of Public Health, Boston, MA, USA

Department of Environmental Health

${ }^{4}$ Municipal Children's Hospital, Kraków, Poland

\begin{abstract}
Objectives: The main goal of the study was to assess possible association between fetal exposure to fine particulate matter $\left(\mathrm{PM}_{2.5}\right)$ and exhaled carbon monoxide (eCO) measured in non-asthmatic children. Material and Methods: The subjects include 118 children taking part in an ongoing population-based birth cohort study in Kraków. Personal samplers of $\mathrm{PM}_{25}$ were used to measure fine particle mass in the fetal period and carbon monoxide (CO) in exhaled breath from a single exhalation effort at the age of 7 . In the statistical analysis of the effect of prenatal $\mathrm{PM}_{2.5}$ exposure on eCO, a set of potential confounders, such as environmental tobacco smoke (ETS), city residence area, sensitization to house dust allergens and the occurrence of respiratory symptoms monitored over the seven-year follow-up was considered. Results: The level of eCO did not correlate with the self-reported ETS exposure recorded over the follow-up, however, there was a positive significant relationship with the prenatal $\mathrm{PM}_{25}$ exposure (non-parametric trend $\mathrm{p}=0.042$ ). The eCO mean level was higher in atopic children (geometric mean $=2.06 \mathrm{ppm}, 95 \% \mathrm{CI}: 1.58-2.66 \mathrm{ppm}$ ) than in non-atopic ones (geometric mean $=1.57 \mathrm{ppm}, 95 \% \mathrm{CI}: 1.47-1.73 \mathrm{ppm})$ and the difference was statistically significant $(\mathrm{p}=0.036)$. As for the respiratory symptoms, eCO values were associated positively only with the cough severity score recorded in the follow-up (nonparametric trend $\mathrm{p}=0.057)$. In the nested multivariable linear regression model, only the effects of prenatal $\mathrm{PM}_{2.5}$ and cough severity recorded in the follow-up were related to eCO level. The prenatal $\mathrm{PM}_{25}$ exposure represented 5.1\%, while children's cough represented only $2.6 \%$ of the eCO variability. Conclusion: Our study suggests that elevated eCO in non-asthmatic children may result from oxidative stress experienced in the fetal period and that heme oxygenase (HO) activity in body tissues may be programmed in the fetal period by the exposure to fine particulate matter.
\end{abstract}

Key words:

Exhaled CO, Prenatal exposure, Fine particulate matter, Healthy non-asthmatic children

The study was partly supported by the grant from the International Center for Studies and Research in Biomedicine, Luxembourg. Received: February 27, 2012. Accepted: July 24, 2012.

Corresponding author: W. Jędrychowski, Chair of Epidemiology and Preventive Medicine, Jagiellonian University Medical College, Kopernika 7a, 31-034 Kraków, Poland (e-mail: myjedryc@cyf-kr.edu.pl). 


\section{INTRODUCTION}

Exhaled carbon monoxide (eCO) measurements have initially been used for the assessment of ambient exposure to $\mathrm{CO}$ and tobacco smoking; however, it was found later that $\mathrm{CO}$ is also formed within the body irrespective of the environmental exposure [1,2]. Furthermore, it was observed that under physiological conditions $\mathrm{CO}$ is present in measurable concentrations in the exhaled air of healthy individuals, and its levels may be elevated in numerous inflammatory states. Increased eCO levels have been found in the patients with asthma during the periods of non-steroid therapy and asthma exacerbations, [3,4] during upper and lower respiratory infections [5-8], and in atopic subjects as a result of allergen challenge [9-11].

Enzymatic degradation of heme and non-heme-related release (lipid peroxidation, xenobiotics, bacteria) are two major sources of endogenous $\mathrm{CO}$. The predominant endogenous source of $\mathrm{CO}$ (about $85 \%$ ) in the body is from the degradation of hemoglobin by the enzyme heme oxygenase (HO) and the rest arises from degradation of myoglobin, catalase, Nitric Oxide synthase, guanylyl synthase, and cytochromes [12,13]. Endogenous CO does not undergo further metabolism in the body, and as a gas secreted by lungs can be measured in exhaled breath from a single exhalation effort.

The observed association between the increased expression of the inducible isoform (HO-1) in alveolar macrophages and higher levels of exhaled CO in asthmatic subjects led to the hypothesis that $\mathrm{eCO}$ may be a biomarker of heme oxygenase (HO) enzyme activity within the respiratory tract, which reflects oxidative stress-related bronchial inflammation [14-16]. However, further studies have shown that HO may be induced also in other body tissues by cellular oxidative stress, which is a key mechanism of the adverse health effects attributed to metal-generated free radicals, fine particulate matter and organic compounds [17]. Recent studies have confirmed that $\mathrm{CO}$ in the expired air is a very sensitive marker of oxidative stress caused by the exposure to diesel exhaust particulates [18]. The ambient fine particles are virtually always present in particle-generating processes, especially combustion processes that generate other toxic agents as well. Typically, the ambient fine-particle fractions contain constituents of tobacco, organic compounds, sulfates, polycyclic aromatic hydrocarbons, metals and many other chemicals [19]. While most of the studies were concerned with the importance of eCO for clinical diagnosis or various other respiratory disorders in adults and children, there is a scarcity of studies in humans about the potential effect of ambient pollutants on exhaled $\mathrm{CO}$ as a potential marker of oxidative stress. The present study was done to assess the hypothesis that the prenatal $\mathrm{PM}_{2.5}$ exposure may increase and program $\mathrm{HO}$ activity level in the vulnerable fetal period and lead to higher eCO values in later life. As the asthmatic children may have symptomatic or subclinical airway inflammation associated with elevated eCO level, the study has been limited to non-asthmatic children who were free from current respiratory symptoms one month prior to eCO measurements. In the statistical evaluation of the effect caused by the fetal $\mathrm{PM}_{2.5}$ exposure on eCO in 7-year olds, a set of potential confounders, such as environmental tobacco smoke (ETS), city residence area, atopy, history of respiratory symptoms, such as cough, wheezing and difficult breathing regularly monitored from birth of children was accounted for.

\section{MATERIAL AND METHODS}

The subjects include 118 children selected from the group of 132 children at the age of 7 who attended eCO testing and are participants of an ongoing longitudinal study on the health impact of prenatal exposure to outdoor/indoor air pollution in infants and children from the Kraków inner city area (principal investigator of the study is Prof. Perera from Columbia Center for Children's Environmental Health, Mailman School of Public Health, Columbia 
University, New York, US). The selected children were non-asthmatic, term born (> 36 weeks of gestation) and took part in all regular health check-ups in the follow-up period. The detailed description of the study design was presented elsewhere [20]. In short, pregnant women were recruited from ambulatory prenatal clinics in the first or second trimester of pregnancy. The study included women between 18 and 35 years of age, who claimed to be nonsmokers, with singleton pregnancies, without illicit drug use and HIV infection, free from chronic diseases such as diabetes or hypertension, and residents of Kraków for at least one year prior to pregnancy. All women participating in the study had read and signed informed consent. The Jagiellonian University Ethical Committee approved the research.

Upon enrollment, a detailed questionnaire was administered to each subject to obtain information on demographic data, house characteristics, medical history of mothers, and smoking practices of others present in the home. Over the seven-year follow-up, regular data on the occurrence of respiratory diseases and symptoms, such as cough, difficult breathing, wheezing spells and their duration were collected by interviewers visiting homes of children at intervals of 3 months in the first two years of life and every 6 months later. Environmental tobacco smoke (ETS) was assumed, if at least one of the household members was an active smoker over the follow-up period. Atopic status of children was defined as the sensitization to at least one common aeroallergen (Der f1, Der p1, Can f1 and Fel d1) measured by the skin prick testing (SPT) at the age of 5 years.

\section{Exhaled CO measurements}

Levels of exhaled carbon monoxide (eCO) were assessed by the new electronic portable battery-operated Bedfont EC50 analyzer (Bedfont Technical Instruments Ltd. Sittingbourne UK) designed to measure end-expired (alveolar) $\mathrm{CO}$. The instrument samples $\mathrm{CO}$ by diffusion from expired air trapped over the sensor (lowest limit of detection $1 \mathrm{ppm}$ ) in a one-way valve.

The measurement is non invasive, requires little technical expertise and is easy to perform in older children. The measurements were performed only in children who were free from any chest symptoms, rhinitis or eczema one month prior to the examination and were not on any medical therapy. On three consecutive occasions children were asked to inhale in the morning ambient air to near total lung capacity and exhale through a mouthpiece into the device for 15 seconds at a constant exhalation flow rate $(50 \mathrm{ml} / \mathrm{s})$. Exhaled $\mathrm{CO}$ was detectable in all children. Out of three expiratory efforts performed by a child the highest value was considered in the analysis. Expired CO concentrations measured by the Bedfont EC50 analyzer were found to correlate closely with blood carboxyhemoglobin $[21,22]$.

\section{Dosimetry of fine particulate matter}

A Personal Environmental Monitoring Sampler (PEMS) developed by the Department of Environmental Health at Harvard University (Dr. John D. Spengler) was used to measure fine particle mass. A member of the air monitoring staff instructed the women on how to use the personal monitor, which is lightweight and silent device worn in a small backpack. They were asked to wear the monitor during daytime hours for 2 consecutive days and place the monitor near their bed at night.

The PEMS was designed to acquire the particle target size of $\leq 2.5 \mu \mathrm{m}$ at a flow rate of $2.01 / \mathrm{min}$ (LPM). Flow rates were calibrated (with filters in place) using a bubble meter prior to the monitoring, and were checked again at the change of the battery pack on the second day and at the conclusion of the monitoring after a 48-hour period. The particles were collected on a Teflon membrane filter $\left(37 \mathrm{~mm} \mathrm{Teflo}{ }^{\mathrm{TM}}\right.$, Gelman Sciences). The combination of low-pressure drop (permitting the use of a low power sampling pump), low hygroscopicity (minimizing bound 
water interference in mass measurements), and low trace element background (improving analytical sensitivity) of these filters makes them highly appropriate for personal particle sampling.

\section{Ascertainment of atopic status}

At the age of 5, the children who attended the follow-up were invited to undergo SPT for 4 common domestic aeroallergens (Dermatophagoides pteronyssinus, Dermatophagoides farinae, dog and cat hair). The results were read after $15 \mathrm{~min}$ by measuring the largest diameter of the wheal. Atopic statuses were ascertained as a wheal-reaching diameter of $3 \mathrm{~mm}$ and greater than the histamine control. The participants were defined as atopic if they had at least one positive skin prick test.

\section{Statistical analysis}

Statistical analysis was performed in order to assess a possible association between eCO measured in 7-year-olds and prenatal personal exposure to $\mathrm{PM}_{2.5}$. As the distributions of eCO and $\mathrm{PM}_{2.5}$ were skewed, in the statistical analysis, we used lognormal-transformed values, which satisfactory normalized the distribution, and the levels were given as geometric mean values (average after logtransformation, followed by back transformation) together with $95 \%$ confidence intervals. In the initial univariate analysis the differences in continuous variables between groups were analyzed using one-way analysis of variance; differences in the frequencies of categorical variables were evaluated with Chi-square test. The descriptive univariate analysis was followed by the nested multivariable linear regression model, which explored the relationship between the dependent variable (eCO log-transformed) and main exposure variable (prenatal $\mathrm{PM}_{2.5} \log$-transformed) and adjusted for a set of a priori selected covariates, such as severity of respiratory symptoms and atopic status. The occurrence of respiratory symptoms monitored from the birth of children over the follow-up (duration of symptoms in days) was scored in tertiles of their distributions and atopy as a nominal variable. This nested regression model tests the significance of independent variables entered in a hierarchical sequence, each step adding another block (variable) in the model. The regressions are nested in the sense that the first block of variable(s) is nested in the second one since all regression predictors in the first model are included in the second. Similarly, the second regression coefficients are nested in the third regression model and so on. The procedure reports listing of the variables entered with each block and increments in $\mathrm{R}^{2}$ and whether these are statistically significant. After the last block is added, the table summarizes the change in $\mathrm{R}^{2}$ for each block of variables together with $\mathrm{F}$ test for its significance. The nested regression model is appropriate to estimate the effect of main independent variable (exposure) on a given outcome after controlling for the background variables. In the regression model, only cases with complete set of covariates were considered. Statistical analyses were performed by using the statistical software STATA version 12.1.

\section{Results}

In the study sample the geometric mean of eCO was 1.6 ppm (95\% CI: $1.5-1.8)$ and $45 \%$ of subjects showed $1 \mathrm{ppm}$. There was no difference in the characteristics of children grouped by the lowest detecting limit of eCO (Table 1) and the children attending and non-attending eCO testing, except for those with higher eCO levels who reported slightly more days with difficult breathing (Table 2).

The level of eCO did not correlate with the self-reported ETS exposure recorded over the follow-up or residence area, however, there was a positive significant relationship with the prenatal $\mathrm{PM}_{2.5}$ exposure categorized in tertiles (non-parametric trend $\mathrm{p}=0.042$ ).

In atopic children $(\mathrm{N}=21)$, the level of eCO was much higher (geometric mean $=2.06,95 \%$ CI: $1.58-2.66$ ) than 
Table 1. Characteristics of children included in the analyses grouped by the median level of exhaled CO

\begin{tabular}{|c|c|c|c|c|}
\hline Variables & $\begin{array}{l}\text { Lowest detectable } \\
\text { level of eCO } \\
(\leq 1 \mathrm{ppm}) \\
(\mathrm{N}=53) \\
\mathrm{n}(\%)\end{array}$ & $\begin{array}{c}\text { Higher level of eCO } \\
\begin{array}{c}(>1 \mathrm{ppm}) \\
(\mathrm{N}=65) \\
\mathrm{n}(\%)\end{array}\end{array}$ & $\begin{array}{c}\text { Total } \\
(\mathrm{N}=118) \\
\mathrm{n}(\%)\end{array}$ & $\mathrm{p}$ for difference \\
\hline Gender of child: boys & $26(49.1)$ & $36(55.4)$ & $62(52.5)$ & 0.6175 \\
\hline Maternal atopy: yes & $13(24.5)$ & $13(20.0)$ & $26(22.0)$ & 0.7136 \\
\hline \multicolumn{5}{|l|}{ ETS } \\
\hline $\begin{array}{l}0 \\
1-3\end{array}$ & $\begin{array}{r}38(82.6) \\
6(13.0)\end{array}$ & $\begin{array}{r}46(73.0) \\
9(14.3)\end{array}$ & $\begin{array}{l}84(77.1) \\
15(13.8)\end{array}$ & \multirow[t]{3}{*}{0.3060} \\
\hline$>3$ & $2(4.3)$ & $8(12.7)$ & $10(9.2)$ & \\
\hline missing data & 7 & 2 & 9 & \\
\hline \multicolumn{5}{|l|}{$\mathrm{PM}_{2.5}$ (in tertiles) $\left(\mu \mathrm{g} / \mathrm{m}^{3}\right)$} \\
\hline$\leq 26.0$ & $19(35.8)$ & $18(27.7)$ & $37(31.4)$ & \multirow[t]{3}{*}{0.2092} \\
\hline $26.1-38.0$ & $18(34.0)$ & $17(26.2)$ & $35(29.7)$ & \\
\hline$>38.0$ & $16(30.2)$ & $30(46.2)$ & $46(39.0)$ & \\
\hline \multicolumn{5}{|l|}{ Cough days } \\
\hline $0-101$ & $16(34.8)$ & $16(25.4)$ & $32(29.4)$ & \multirow[t]{4}{*}{0.4884} \\
\hline $102-214$ & $21(45.7)$ & $30(47.6)$ & $51(46.8)$ & \\
\hline$\geq 215$ & $9(19.6)$ & $17(27.0)$ & $26(23.9)$ & \\
\hline missing data & 7 & 2 & 9 & \\
\hline \multicolumn{5}{|l|}{ Wheezing days } \\
\hline 0 & $29(63.0)$ & $33(52.4)$ & $62(56.9)$ & \multirow[t]{4}{*}{0.5207} \\
\hline $1-12$ & $12(26.1)$ & $20(31.7)$ & $32(29.4)$ & \\
\hline$\geq 13$ & $5(10.9)$ & $10(15.9)$ & $15(13.8)$ & \\
\hline missing data & 7 & 2 & 9 & \\
\hline \multicolumn{5}{|l|}{ Difficult breathing } \\
\hline 0 & $24(52.2)$ & $26(41.3)$ & $50(45.9)$ & \multirow[t]{4}{*}{0.3545} \\
\hline $1-13$ & $11(23.9)$ & $23(36.5)$ & 34 (31.2) & \\
\hline$\geq 14$ & $11(23.9)$ & $14(22.2)$ & $25(22.9)$ & \\
\hline missing data & 7 & 2 & 9 & \\
\hline
\end{tabular}

ETS - environmental tobacco smoke, $\mathrm{PM}_{2.5}$ - particulate matter.

in non-atopic (geometric mean $=1.57,95 \%$ CI: $1.47-$ $1.73)$ and the difference was statistically significant $(\mathrm{p}=0.036)$. Interestingly, the prenatal $\mathrm{PM}_{2.5}$ did not correlate with eCO level in the atopic children (Spearman rho $=-0.321, p=0.208)$. As for the respiratory symptoms reported in the follow-up, the level of the eCO was associated positively only with the cough score (nonparametric trend $p=0.057)$, but not with wheezing $(p=0.293)$ or difficult breathing $(\mathrm{p}=0.758)$ scores.

Table 3 presents the results of the nested linear regression model of eCO (log-transformed values) on prenatal $\mathrm{PM}_{2.5}$ exposure (log-transformed) respiratory symptoms and 
Table 2. Characteristics of children under study grouped by the attendance to $\mathrm{CO}$ measurements

\begin{tabular}{|c|c|c|c|c|}
\hline Variables & $\begin{array}{c}\text { Attending } \\
(\mathrm{N}=132) \\
\mathrm{n}(\%)\end{array}$ & $\begin{array}{l}\text { Non-attending } \\
\begin{array}{c}(\mathrm{N}=168) \\
\mathrm{n}(\%)\end{array}\end{array}$ & $\begin{array}{c}\text { Total } \\
(\mathrm{N}=300) \\
\mathrm{n}(\%)\end{array}$ & $\mathrm{p}$ for difference \\
\hline Gender of child: boys & $71(53.8)$ & $78(46.4)$ & $149(49.7)$ & 0.2505 \\
\hline $\begin{array}{l}\text { Atopy: yes } \\
\text { missing data }\end{array}$ & $\begin{array}{c}17(14.9) \\
18\end{array}$ & $\begin{array}{c}17(14.0) \\
47\end{array}$ & $\begin{array}{c}34(14.5) \\
65\end{array}$ & 0.9981 \\
\hline Maternal atopy: yes & $28(21.2)$ & $40(23.8)$ & $68(22.7)$ & 0.6932 \\
\hline \multicolumn{5}{|l|}{$\mathrm{PM}_{2.5}\left(\mu \mathrm{g} / \mathrm{m}^{3}\right)$} \\
\hline mean & 40.482 & 43.067 & 41.926 & 0.4173 \\
\hline standard deviation & 25.982 & 28.351 & 27.316 & \\
\hline missing data & 0 & 1 & 1 & \\
\hline \multicolumn{5}{|l|}{ ETS } \\
\hline 0 & $94(77.0)$ & $118(73.3)$ & $212(74.9)$ & 0.5193 \\
\hline $1-3$ & $18(14.8)$ & $23(14.3)$ & $41(14.5)$ & \\
\hline$>3$ & $10(8.2)$ & $20(12.4)$ & $30(10.6)$ & \\
\hline missing data & 10 & 7 & 17 & \\
\hline \multicolumn{5}{|l|}{ Cough days } \\
\hline 0-101 & $33(27.0)$ & $38(23.6)$ & $71(25.1)$ & 0.6524 \\
\hline $102-214$ & $57(46.7)$ & $84(52.2)$ & $141(49.8)$ & \\
\hline$\geq 215$ & $32(26.2)$ & $39(24.2)$ & $71(25.1)$ & \\
\hline missing data & 10 & 7 & 17 & \\
\hline \multicolumn{5}{|l|}{ Wheezing days } \\
\hline 0 & $65(53.3)$ & $76(47.2)$ & $141(49.8)$ & 0.1686 \\
\hline $1-12$ & $34(27.9)$ & $39(24.2)$ & $73(25.8)$ & \\
\hline$\geq 13$ & $23(18.9)$ & $46(28.6)$ & $69(24.4)$ & \\
\hline missing data & 10 & 7 & 17 & \\
\hline \multicolumn{5}{|l|}{ Difficult breathing } \\
\hline 0 & $55(45.1)$ & $54(33.5)$ & $109(38.5)$ & 0.0901 \\
\hline $1-13$ & $37(30.3)$ & $51(31.7)$ & $88(31.1)$ & \\
\hline$\geq 14$ & $30(24.6)$ & $56(34.8)$ & $86(30.4)$ & \\
\hline missing data & 10 & 7 & 17 & \\
\hline
\end{tabular}

Abbreviations the same as in Table 1.

atopy. It was revealed that only the effects of $\mathrm{PM}_{2.5}$ and cough remained significant. The interaction term between both covariates was insignificant. The covariates considered in the regression model explained $9.5 \%$ of the total eCO variability. While the prenatal $\mathrm{PM}_{2.5}$ exposure contributed by $5.1 \%$ in explaining the eCO variability, children's cough contributed a little less (2.6\%). Figure 1 shows the dose-dependent relationship between eCO levels and prenatal $\mathrm{PM}_{2.5}$ exposure in children grouped by the cough scores. 
Table 3. Summary of hierarchical regression analysis for variables predicting eCO values (log-transformed) in 7-year olds $(\mathrm{N}=107)^{*}$

\begin{tabular}{|c|c|c|c|c|c|c|}
\hline Variables & B coeff. & SE B & p level & R-square & $\begin{array}{l}\text { Change in } \\
\text { R-square }\end{array}$ & $\begin{array}{l}\text { F for change in } \\
\text { R-square }\end{array}$ \\
\hline \multicolumn{7}{|l|}{ Model I } \\
\hline prenatal $\mathrm{PM}_{2.5}$ exposure & 0.190 & 0.080 & 0.019 & 0.051 & & $\begin{array}{c}3.64 \\
p=0.019\end{array}$ \\
\hline \multicolumn{7}{|l|}{ Model II } \\
\hline prenatal $\mathrm{PM}_{2.5}$ exposure & 0.193 & 0.080 & 0.018 & \multirow[t]{2}{*}{0.058} & \multirow[t]{2}{*}{0.007} & 0.75 \\
\hline wheezing score & 0.044 & 0.051 & 0.389 & & & $p=0.389$ \\
\hline \multicolumn{7}{|l|}{ Model III } \\
\hline prenatal $\mathrm{PM}_{2.5}$ exposure & 0.202 & 0.080 & 0.013 & \multirow[t]{3}{*}{0.084} & \multirow[t]{3}{*}{0.026} & 2.94 \\
\hline wheezing score & 0.029 & 0.052 & 0.567 & & & $\mathrm{p}=0.089$ \\
\hline cough score & 0.094 & 0.055 & 0.090 & & & \\
\hline \multicolumn{7}{|l|}{ Model IV } \\
\hline prenatal $\mathrm{PM}_{2.5}$ exposure & 0.204 & 0.080 & 0.012 & \multirow[t]{4}{*}{0.086} & \multirow[t]{4}{*}{0.002} & 0.26 \\
\hline wheezing score & 0.038 & 0.054 & 0.484 & & & $p=0.609$ \\
\hline cough score & 0.097 & 0.055 & 0.082 & & & \\
\hline difficult breathing score & -0.029 & 0.057 & 0.509 & & & \\
\hline \multicolumn{7}{|l|}{ Model V } \\
\hline prenatal $\mathrm{PM}_{2.5}$ exposure & 0.177 & 0.085 & 0.039 & \multirow[t]{5}{*}{0.095} & \multirow[t]{5}{*}{0.009} & \multirow{5}{*}{$\begin{array}{c}0.98 \\
p=0.324\end{array}$} \\
\hline wheezing score & 0.036 & 0.054 & 0.510 & & & \\
\hline cough score & 0.094 & 0.055 & 0.093 & & & \\
\hline difficult breathing score & -0.026 & 0.057 & 0.637 & & & \\
\hline atopy & 0.126 & 0.127 & 0.324 & & & \\
\hline
\end{tabular}

* Respiratory symptom scores for cough, wheezing and difficult breathing were based on the occurrence of symptoms recorded in the seven-year follow-up.

$\mathrm{SE} \mathrm{B}$ - standard error of B coefficient, $\mathrm{PM}_{2.5}$ - particulate matter.

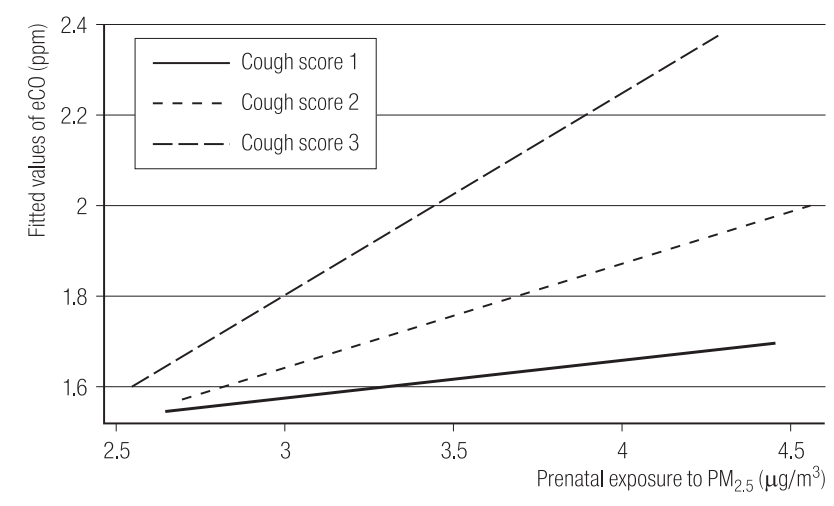

Fig. 1. Trends of eCO values vs. the prenatal $\mathrm{PM}_{25}$ exposure (In-transformed) in children grouped by the cough scores recorded in the follow-up (linear regression fitting)

\section{DISCUSSION}

The study provided evidence that individual variability of eCO values in children may be related to the respiratory symptoms and fetal exposure to fine particulate matter. The children who underwent eCO testing in our study did not present any current respiratory symptoms for one month before testing and were non-asthmatic. Except for the history of coughing, neither the severity of wheezing nor difficult breathing monitored over the follow-up since birth were significantly associated with exhaled CO levels. 
It is worth mentioning that the observed dose-dependent relationship without threshold was seen between $\mathrm{eCO}$ and fetal exposure to $\mathrm{PM}_{2.5}$ and that the significant portion of the exhaled $\mathrm{CO}$ could be attributed to prenatal $\mathrm{PM}_{2.5}$ exposure. This could be explained by upgraded heme oxygenase activity possibly induced by the prenatal exposure to fine particulates in fetal body tissues might persist later in life and lead to the increased excretion of $\mathrm{CO}$ by alveoli. The reason to consider alveoli as the main site of exhaled $\mathrm{CO}$ is based on the observation that levels of $\mathrm{CO}$ measured at the end of exhalation are similar to those sampled by bronchoscope from the main bronchus. Exhaled CO levels are not flow-dependent, and highest CO levels are seen close to the end of exhalation [23-25]. However, a small proportion of eCO in the children with the history of coughing recorded in the follow-up, might have been produced in the upper airways and transported to the lower respiratory tract or reflect an enhanced $\mathrm{CO}$ production in the lower airways due to an ongoing subclinical inflammation. An alternative interpretation is that the prenatal exposure to fine particulate matter may be a proxy for the current exposure to the environmental factors implicated in generating oxidative stress, which might be the reason for the increased eCO levels.

The mean exhaled CO levels observed in our study sample were lower than those observed in asthmatic children and in patients with other respiratory disorders. Uausuf et al. [26] found eCO levels significantly higher $(2.17 \pm 0.21)$ in children with persistent asthma compared to those with sporadic episodic asthma $(1.39 \pm 0.18)$ and healthy children $(1.01 \pm 0.12 \mathrm{ppm})$. As shown by Zayasu et al. [27] asthmatic adults had eCO concentrations still higher (5.6 $\pm 0.6 \mathrm{ppm})$ compared to nonsmoking healthy control subjects $(1.5 \pm 0.1 \mathrm{ppm})$. However, non-asthmatic subjects with the symptoms of upper respiratory tract infections also presented eCO levels significantly elevated during the acute phase of the infection compared to recovery values $(5.6 \pm 0.4 \mathrm{ppm}$ vs. $1.0 \pm 0.1 \mathrm{ppm})$, which were similar to those in age-matched healthy non-smokers [6]. Moreover, elevated eCO levels were reported in asymptomatic but atopic individuals. For instance, Horvath et al. [9] in healthy non-smoking asymptomatic atopic adults compared with non-atopic individuals also demonstrated significantly elevated eCO values ( $4.7 \pm 0.3$ ppm vs. $2.8 \pm 0.2 \mathrm{ppm})$. On average, eCO levels measured in our population sample exposed to prenatal $\mathrm{PM}_{2.5}$ levels were similar to those observed in nonsmoking adults and healthy asymptomatic children reported from the Horvath studiy quoted above. The biological mechanisms whereby eCO might be explained by the prenatal $\mathrm{PM}_{2.5}$ exposure are not yet clear enough. $\mathrm{PM}_{2.5}$ is a proxy of a wide spectrum of environmental hazards that may be involved in generating oxidative stress [17-19]. It is important to mention that fine particles containing very high proportion of organic carbon has relevance to the biologic potency of these particles, which is strongly correlated with the PAH content and oxidative stress inducing $\mathrm{HO}$ activity in body tissues. Many studies provided evidence that $\mathrm{HO}$ plays a key role in maintaining cellular and tissue homeostasis and has a potential antioxidant and cytoprotective effect, which is linked with the antioxidative function of end-products of heme degradation, such as CO or bilirubin [12,28]. However, it is likely that the excessive production of endproducts of heme degradation by $\mathrm{HO}$ may lead to the tissue damage.

Epigenetic studies examining gene-air pollution exposure interactions may shed more light on the biological mechanisms by which air pollution affects human health. A new hypothesis suggests that a greater susceptibility to air pollutants may be linked with genomic polymorphism [29] and reduced levels of DNA methylation associated with oxidative stress, by altering the expression of genes involved in the methylation process. In the context of potential epigenetic effects of air pollutants, we have to mention observations made recently by Perera et al. [30] in the New York City cohort study on fetal growth and healthy development of children. In the latter study, prenatal exposure 
to polycyclic aromatic hydrocarbons (PAHs) was significantly associated with genomic hypomethylation in cord blood white cell's DNA and showed the potential for epigenetic changes lasting even several years after exposures. Strength of our study is the prospective cohort design, which enabled us to measure the association between prenatal personal $\mathrm{PM}_{2.5}$ exposures in the second trimester of pregnancy with subsequent eCO values measured in 7-year-old children. This age group is very seldom affected by high ambient $\mathrm{CO}$ exposure resulting from environmental tobacco or other sources of exposure, which may considerably skew the eCO measurements. A very strong advantage of the study is that relevant confounder, such as asthma, has been removed through inclusion criteria. Another strong point of the study is the application in the risk assessment of personal exposure techniques, integrating both outdoor and indoor exposures. On the other hand, we are aware of the limitations of our study, which are mainly related to the relatively small study sample and the scarcity of relevant data on current environmental exposure. Although the sample of pregnant women was recruited from the general population of the Kraków inner city area inhabited by a relatively homogenous population in terms of socio-economic status, the sample is not representative of this population because of the inclusion criteria. Moreover, exhaled CO measurements performed by the electronic $\mathrm{CO}$ monitor may not precisely reflect the endogenous production of $\mathrm{CO}$. Having a longer series of eCO measurements carried out in various seasons would produce more precise estimates of the effect. We believe that our study, despite these limitations, has provided additional arguments for the hypothesis stating that the exhaled CO level may be programmed in the fetal period through the $\mathrm{HO}$ induction and oxidative stress mechanisms; however, the results require further research on the causality of the discussed relationship.

In closing, our study suggests that elevated eCO in non-asthmatic children free from current respiratory symptoms may result from oxidative stress experienced in the fetal period, and that $\mathrm{HO}$ activity in body tissues may be programmed in the fetal period by the exposure to fine particulate matter.

\section{REFERENCES}

1. Sjostrand T. Endogenous production of carbon monoxide in man under normal and pathophysiological conditions. Scand J Clin Lab Invest 1949;1:201-14.

2. Sjostrand T. The formation of carbon monoxide by the decomposition of hemoglobin in vivo. Acta Physiol Scand 1952;26:338-44.

3. Uasuf CG, Jatakanon A, James A, Sergei A, Kharitonov MD, Nicola M, et al. Exhaled carbon monoxide in childhood asthma. J Pediatr 1999;135:569-74.

4. Yamaya M, Sekizawa K, Ishizuka S, Monma M, Sasaki H. Exhaled carbon monoxide levels during treatment of acute asthma. Eur Respir J 1999;13:757-60.

5. Andersson JA, Uddman R, Tajti J, Cardell LO. Heme oxygenase and nitric oxide synthase in human middle ear epithelium indicates local carbon monoxide and nitric oxide production. Acta Otolaryngol 2002;122:634-7.

6. Yamaya M, Sekizawa K, Ishizuka S, Monma M, Mizuta K, Sasaki H. Increased carbon monoxide in exhaled air of subjects with upper respiratory tract infections. Am J Respir Crit Care Med 1998;158:311-4.

7. Biernacki WA, Kharitonov SA, Barnes PJ. Exhaled carbon monoxide in patients with lower respiratory tract infection. Respir Med 2001;95:1003-5.

8. Andersson JA, Uddman R, Cardell LO. Increased carbon monoxide levels in the nasal airways of subjects with a history of seasonal allergic rhinitis and in patients with upper respiratory tract infection. Clin Exp Allergy 2002;32:224-7.

9. Horvath I, Barnes PJ. Exhaled monoxides in asymptomatic atopic subjects. Clin Exp Allergy 1999;29:1276-80.

10. Paredi P, Leckie MJ, Horvath I, Allegra L, Kharitonov SA, Barnes PJ. Changes in exhaled carbon monoxide and nitric oxide levels following allergen challenge in patients with asthma. Eur Respir J 1999;13:48-52. 
11. Monma M, Yamaya M, Sekizawa K, Ikeda K, Suzuki N, Kikuchi T, et al. Increased carbon monoxide in exhaled air of patients with seasonal allergic rhinitis. Clin Exp Allergy 1999;29:1537-41.

12. Maines MD. Heme oxygenase: function, multiplicity, regulatory mechanisms, and clinical application. FASEB J 1998;2: 2557-68.

13. Kharitonov SA, Barnes PJ. Exhaled nitric oxide, carbon monoxide, and breath condensate. In: Marczin N, Kharitonov SA, Yacoub MH, Barnes PJ, editors. Disease markers in exhaled breath. New York-Basel: Marcel Dekker, Inc; 2003. p. 199-218.

14. Horvath I, Donnelly L E, Kiss A, Paredi P, Kharitonov SA, Barnes PJ. Raised levels of exhaled carbon monoxide are associated with an increased expression of heme oxygenase-1 in airway macrophages in asthma: a new marker of oxidative stress. Thorax 1998;53:668-72.

15. Lim S, Groneberg D, Fischer A, Oates T, Caramori G, Mattos W, et al. Expression of heme oxygenase isoenzymes 1 and 2 in normal and asthmatic airways: effect of inhaled corticosteroids. Am J Respir Crit Care Med 2000;162:1912-8.

16. Harju T, Soini Y, Paakko R Kinnula VL. Up-regulation of heme oxygenase-I in alveolar macrophages of newly diagnosed asthmatics. Respir Med 2002;96:418-23.

17. Donaldson K, Stone V, Borm PJA, Jimenez LA, Gilmour PS, Schins RP, et al. Oxidative stress and calcium signaling in the adverse effects of environmental particles (PM10). Free Radical Biol Med 2003;34:1369-82.

18. Nachtingale JA, Maggs R, Cullinan P, Donnelly LE, Rogers DF, Kinnersley R, et al. Airway inflammation after controlled exposure to diesel exhaust particulates. Am J Respir Crit Care Med 2000;162:161-5.

19. Spengler JD, Samet JM, McCarthy JF. Indoor air quality handbook. Chapter 9: Air cleaning-particles. p. 9.1-9.28; Chapter 26: Multiple chemical intolerance and indoor air quality. p. 26.1-26.27. Chapter 70: Risk analysis framework. p. 70.3-70.38. New York: McGraw-Hill; 2001.

20. Jedrychowski W, Whyatt RM, Camann DE, Bawle UV, Peki K, Spengler JD, et al. Effect of prenatal PAH exposure on birth outcomes and neurocognitive development in a cohort of newborns in Poland. Study design and preliminary ambient data. Int J Occup Med Environ Health 2003;16:21-9.

21. Jarvis MJ, Belcher M, Vesey C, Hutchison DC. Low cost carbon monoxide monitors in smoking assessment. Tho$\operatorname{rax} 1986 ; 41: 886-7$.

22. Irving JM, Clark EC, Cromble IK, Smith WC. Evaluation of a portable measure of expired carbon monoxide. Preventive Med 1988;17:109-15.

23. Kharitonov SA, Lim S, Hanazava T, Chung FK, Barnes PJ. Exhaled carbon monoxide derives predominantly from alveoli in healthy non-smokers, smokers and mild stable asthmatics, but also from asthmatic airways after allergen challenge. Am J Respir Crit Care Med 2000;161:A584.

24. Kharitonov SA, Paredi P, Barnes PJ. Methodological aspects of exhaled carbon monoxide measurements as possible noninvasive marker of oxidative stress: influence of exhalation flow, breathholding and ambient air. Eur Respir J 1998;12:128.

25. Beck-Ripp J, Latzin P, Griese M. Exhaled carbon monoxide is not flow dependent in children with cystic fibrosis and asthma. Eur J Med Res 2004;9:518-22.

26. Uasuf CG, Jatakanon A, James A, Kharitonov SA, Wilson NM, Barnes PJ. Exhaled carbon monoxide in childhood asthma. J Pediatr 1999;135:569-74.

27. Zayasu K, Sekizawa K, Okinaga S, Yamaya M, Ohrui T, Sasaki H. Increased carbon monoxide in exhaled air of asthmatic patients. Am J Respir Crit Care Med 1997;156:1140-3.

28. Stocker R, Yamamoto Y, Mac Donagh AF, Glazer AN, Ames BN. Bilirubin is an antioxidant of possible physiological importance. Science 1987;235:1043-6.

29. Baccarelli A, Wright RO, Bollati V, Tarantini L, Litonjua AA, Suh HH, et al. Rapid methylation changes after exposure to traffic particles. Am J Respir Crit Care Med 2009;179: 572-8.

30. Perera FP, Wang S, Vishnevetsky J, Zhang B, Cole KJ, Tang D, et al. Polycyclic aromatic hydrocarbons-aromatic DNA adducts in cord blood and behavior scores in New York City children. Environ Health Perspect 2011;119:1176-81.

This work is available in Open Access model and licensed under a Creative Commons Attribution-NonCommercial 3.0 Poland License - http://creativecommons.org/ licenses/by-nc/3.0/pl/deed.en. 